Bergen Centre for Ethics and Priority Setting (BCEPS), Department of Global Public Health and Primary Care, University of Bergen, Norway

2 Harvard TH Chan School of Public Health, Department of Global Health and Population, Boston, MA, USA

Correspondence to: A Bhopal anand.bhopal@uib.no Cite this as: BMJ 2021;375:e067199 http://dx.doi.org/10.1136//bmj-2021-067199 Published: 28 October 2021

\title{
Priority setting and net zero healthcare: how much health can a tonne of carbon buy?
}

\section{Cutting carbon emissions in healthcare requires trade-offs for clinicians, administrators, and global health policy makers and must be included when evaluating interventions, argue Anand Bhopal and Ole F Norheim}

\section{Anand Bhopal, ${ }^{1}$ Ole F Norheim ${ }^{1,2}$}

The NHS net zero strategy, ${ }^{1}$ launched in October 2020, is the first national strategy of its kind and has helped inspire a global movement for carbon neutral healthcare. ${ }^{2}$ One of two national health sector commitments to be agreed at the United Nations' climate change conference COP26 in Glasgow in November 2021 is to develop a net zero carbon, sustainable health system. ${ }^{3}$ Delivering this agenda will require long term actions to reduce greenhouse gas and carbon emissions. We suggest that mechanisms of priority setting in healthcare could be used to identify and navigate trade-offs in this process.

\section{Healthcare's carbon footprint}

Efforts to decarbonise healthcare are underpinned by the Paris Agreement, the legally binding intergovernmental treaty to limit global temperature rise to below $1.5-2^{\circ} \mathrm{C}$ while pursuing equity, sustainable development, and eradication of poverty. ${ }^{4}$ The lower $1.5^{\circ} \mathrm{C}$ target has growing political ${ }^{5}$ and scientific ${ }^{6}$ support, but the carbon clock is ticking. At current rates, our remaining carbon budget-emissions we can afford to stay below $1.5^{\circ} \mathrm{C}$-will be used up in eight years. ${ }^{7}$

Healthcare is a major polluter. It has the largest carbon footprint of any service sector and is responsible for $4-5 \%$ of global carbon emissions $^{8}$-more than aviation and shipping combined. ${ }^{9}$ The main contributors are medicines (including inhalers), anaesthetic gases, patient and staff transport, heating and cooling of facilities, electricity use, waste management, and food and catering. ${ }^{12}$ Healthcare often constitutes a high proportion of public sector emissions, which, as these are mainly under state and regional public authority control, may merit greater action from government.

Healthcare's carbon footprint can be partly reduced through national and regional structural policies (eg, decarbonising energy supplies), regulations (eg, building efficiency standards), and innovation led approaches (eg, electrified transport networks) only indirectly involving the health sector. It is also possible to substantially reduce emissions through optimising the allocation of resources within the health system.

\section{Carbon as part of priority setting}

Priority setting is widely used throughout healthcare, most notably in the UK through the National Institute of Health and Care Excellence (NICE). The aim is to help policy makers allocate scarce financial resources to improve health fairly and efficiently (box 1). Financial budgets have mostly been met through priority setting and economic growth. The newer and possibly even more important carbon budget is decreasing and finite.

Box 1: Core concepts of priority setting in health

The aim of priority setting is to improve health in a fair and efficient way. Two of the core concepts are resource scarcity-that demand for healthcare outstrips available resources-and opportunity cost-that with each decision comes the loss of a potential benefit had an alternative option been chosen.

Decision making in the context of resource scarcity therefore involves trade-offs. Priority setting exercises often rank services and programmes with the aim of identifying an optimal allocation of resources. In addition, decisions should be reached in a transparent, fair process and revised when new evidence or arguments come to light. This forms the basis of the evaluation of interventions by the National Institute for Health and Care Excellence (NICE) in the UK and the World Bank's Disease Control Priority (DCP) project and WHO-CHOICE globally.

To halt rising temperatures, net zero emissions must be reached globally before the carbon budget is used up. Because of political constraints, the remaining carbon budget is divided through a bottom-up process whereby sectors, businesses, regions, and governments set targets themselves, guided by the fair share principle-balancing the costs and burdens of climate mitigation and adaptation with global responsibilities and the capacity to act. ${ }^{4}$

Growing numbers of healthcare organisations are committing to the goal of net zero. ${ }^{10}$ However, it remains unknown which policies will achieve net zero in healthcare and how to best balance healthcare decarbonisation with other system priorities. There has been little discussion about if, or how, carbon emissions should be integrated into existing priority setting processes. To help clinicians, administrators, and policy makers identify pathways to net zero healthcare that best protect and improve health and global health equity we explore three major dimensions of healthcare's carbon footprint.

\section{Clinical decision making: "on the margins"}

Healthcare's carbon footprint is influenced by several factors, including a shift in clinical decision making towards less carbon emitting procedures. These incremental changes could have a substantial impact over time. Some changes will incur no extra financial 
cost or inconvenience to patients, such as shifting to low carbon inhalers for asthma management or lower carbon anaesthetic gases. ${ }^{11}$ These quick wins should be rapidly implemented. Other interventions may take longer to cut emissions, especially when they challenge clinical norms (eg, reducing unnecessary investigations), location of care (eg, telemedicine), and behaviour (eg, prevention over cure).

A step further is to systematically measure and reduce emissions from treatment pathways. Thiel and colleagues reduced the emissions of a laparoscopic hysterectomy without affecting clinical efficacy by using low emitting anaesthetic agents, reusable instruments, recycling systems, and a renewable electricity supply. ${ }^{12}$ The main contributors to the emissions reduction were switching anaesthetic gases and reducing single use materials, both of which may be cost saving. Better recycling produced only a modest $(<5 \%)$ decrease in emissions. Opportunities to "green" interventions without affecting clinical outcomes are likely to exist across medicine, surgery, and throughout healthcare systems and should be driven by evidence of what works.

There are also potential trade-offs to consider between different interventions for the same treatment. For example, carbon emissions from conventional laparoscopy are 30\% less than from the robot assisted approach, ${ }^{14}$ driven mainly by single use surgical instruments and energy use. Although robot assisted laparoscopy is associated with a slightly shorter length of hospital stay and higher patient satisfaction for some, it is more expensive and more polluting, and there is no strong evidence that it is associated with better treatment outcomes or reduced complications. ${ }^{13}$ Similar differences in carbon emissions between intervention methods are likely to be seen throughout the healthcare system.

Healthcare professionals can contribute to reducing emissions through their daily clinical practice by reducing healthcare overuse, promoting disease prevention, shaping policy guidelines for their specialty, and influencing the healthcare organisation where they work. ${ }^{15}$ Several specialties are already building networks to decarbonise practice while protecting and improving patient health ${ }^{16}{ }^{17}$ and applying a sustainability lens to the quality improvement approach. ${ }^{18}$ Better data on the carbon footprint of healthcare interventions and how to integrate these findings into existing resource allocation criteria could accelerate this work.

\section{Health system perspective: the priority view}

Lifecycle analyses are increasingly used to calculate the environmental impact of healthcare, ranging from entire hospitals ${ }^{19}$ to specific clinical service ${ }^{20}$ and medications. ${ }^{21}$ Implemented at scale, it may be possible to capture the carbon cost of the health benefits gained and incorporate this into health technology assessments. ${ }^{22}$ By setting health system priorities in ways that also take carbon emissions into account, more health could be gained within a given carbon budget.

The highly influential Investing in Health report, published in 1993, examined how much health a million dollars can buy. ${ }^{23}$ Taking inspiration from this work, we have applied a priority setting lens to carbon emissions from the health sector by estimating the disability adjusted life years (DALYs) averted per tonne of carbon (fig 1).

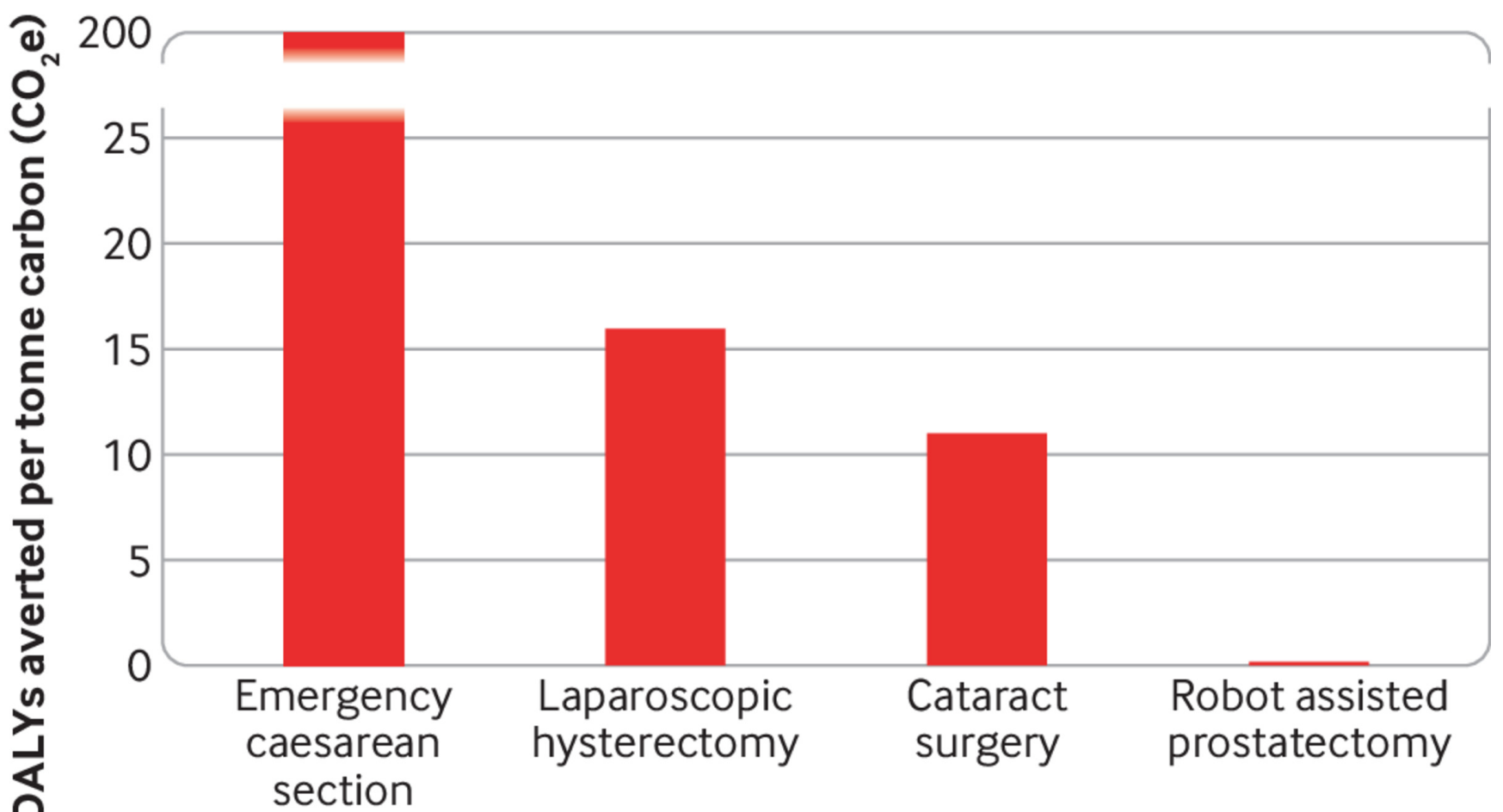

Fig 1 | How much health can a tonne of carbon buy? Estimated carbon costs and health benefits for four interventions in high income countries. Since the data come from highly heterogenous sources ${ }^{1424-29}$ this figure is intended for illustrative purposes only. A 3\% discount rate has been applied to disability adjusted life years (DALYs) averted

In short, a tonne of carbon can buy a lot of health, with huge variation between interventions. For example, there is a 1000 times difference between emergency caesarean section, a lifesaving intervention, and robot assisted prostatectomy, a method that has marginal clinical benefit over conventional laparoscopy. High emitting interventions such as robotic surgery are relevant to health 
technology assessment bodies exploring how to incorporate environmental impact and health opportunity costs into their guidance. Comprehensive work on the carbon emissions of different interventions would help policy makers identify high carbon aspects of the health system and prioritise greener interventions, which could help lower emissions overall.

Few lifecycle analyses have been done in low and middle income settings, where differences are likely to be even higher. In India, the carbon cost of cataract surgery in one site is o.oo6 tonnes ${ }^{30}$ (333 DALYs averted per tonne of carbon), which is far lower carbon than in the UK (o.18 tonnes) despite comparable clinical outcomes and complications rates. ${ }^{31}$

Decarbonising healthcare provides opportunities to improve health but also carries an opportunity cost. Just like high cost initiatives such as the UK's cancer drugs fund displace health from elsewhere in the system, ${ }^{32}$ different pathways to decarbonising healthcare can produce different amounts of health.

\section{Health equity: a global outlook}

Whereas in high income countries the main challenges are managing demand, rising costs, and decreasing healthcare overconsumption, in lower income countries the over-riding challenges remain unmet healthcare needs and applying existing tools to fulfil the promise of global health equity and universal health coverage. By allowing more of the carbon budget to be spent in lower income settings and engaging in priority setting to rapidly reduce the healthcare carbon footprint in higher income settings, greater health gains can be gained more fairly and efficiently.

Figure 2 presents the healthcare carbon footprint and unmet healthcare need by World Bank income group. This shows an inverse relation, with the lowest emissions and highest unmet healthcare needs in low income countries, which are already at greatest risk from the health effects of climate change. ${ }^{6}$

\section{- Healthcare carbon emissions per capita - Unmet healthcare need index}

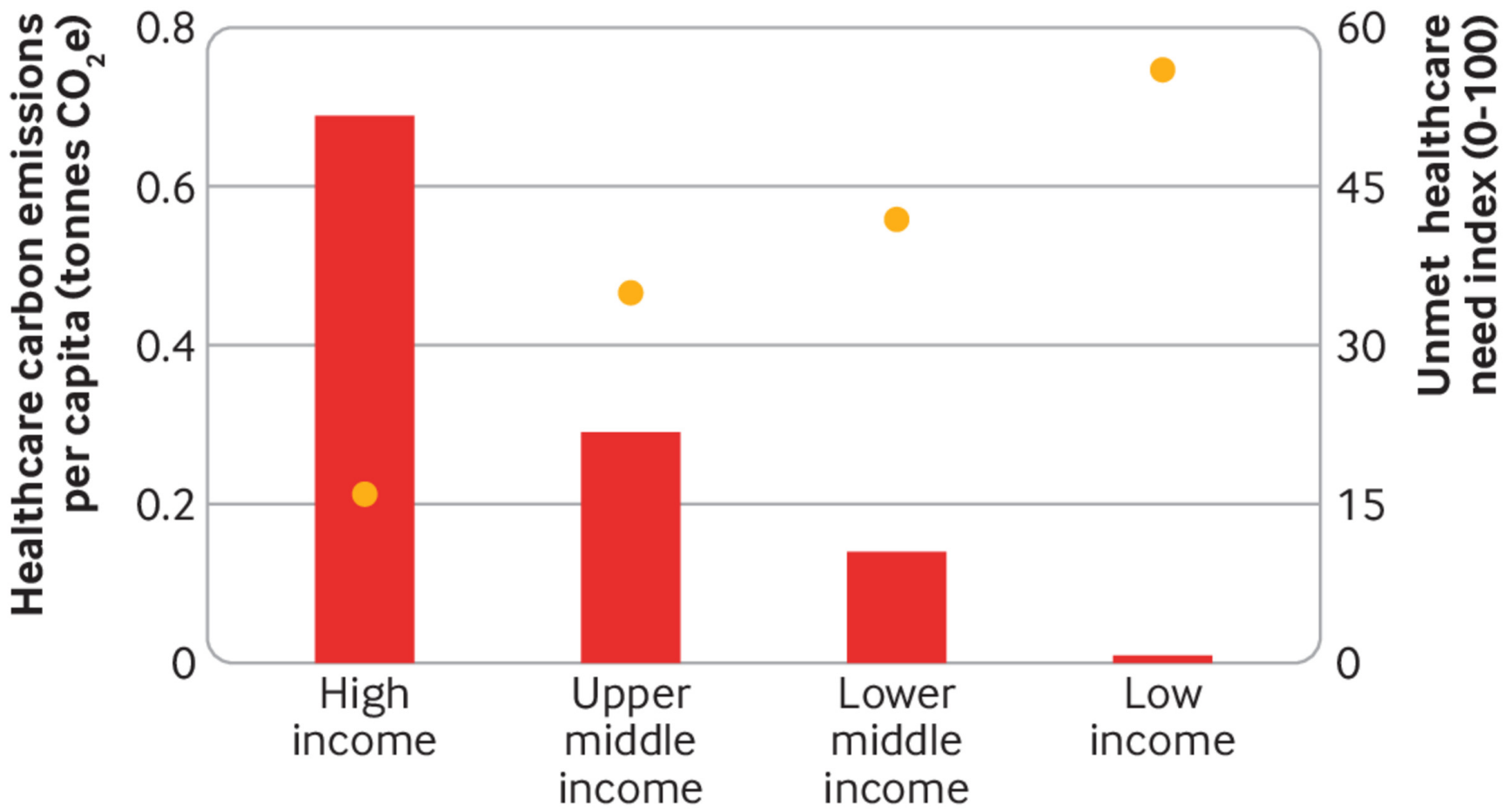

Fig 2 | Average healthcare carbon emissions per capita and unmet healthcare need by World Bank region. Per capita emissions by region are average national per capita emissions. Healthcare emissions for high income and middle income countries taken from Lenzen et al, ${ }^{33}$ low income countries are based on authors' calculation, using an estimate of $5 \%$ of national greenhouse gas emissions from the World Bank. ${ }^{3}$ Unmet need index is the inverse of the healthcare access and quality index from the Global Burden of Disease study ${ }^{35}$

High income countries' per capita emissions are four times greater than those of lower middle income countries and 70 times greater than low income countries. However, this analysis masks even wider differences between countries. For example, healthcare emissions in the US (1.8 tonnes per capita) are nearly three times the average emissions for high income countries.

Cross regional differences in emissions partly reflect healthcare overconsumption (healthcare with no clinical benefit). ${ }^{36}$ The precise figure is contested, but if it were $15 \%$ across high income countries our estimate is that emissions related to overconsumption of healthcare in the European Union are equivalent to total healthcare emissions in sub-Saharan Africa, a region greatly affected by climate change and with twice the population of Europe. ${ }^{6}$ This inequality adds greater impetus to ongoing efforts to rein in healthcare overconsumption.

Many low and middle income countries have substantial and latent unmet health needs, ageing demographics, and growing populations, driving the rise in global healthcare related carbon 
emissions. ${ }^{37}$ This trend could continue, not least because the population of sub-Saharan Africa alone is projected to increase from a billion today to 3.5 billion people by $2100 . .^{38}$ In the near future, building stronger health infrastructure and stronger health systems in these countries will use more materials, more equipment, more medicines-with more emissions. Low and middle income countries should not be locked into highly carbon intensive healthcare; nor should they be required to trade off health for reduced emissions. This cost should fall on high income, high responsibility countries. Incorporating the carbon footprint into healthcare priority setting could help deliver the promise of net zero healthcare globally.

\section{Charting a fair path to net zero}

Although politicians have shown little appetite to reduce carbon emissions from the health sector, especially during the covid-19 pandemic, over 40 healthcare institutions across 16 countries, including in India, South Africa, Brazil, and Australia, have committed to the UN's stringent "race to zero" criteria. ${ }^{10}$ This sort of grassroots initiative was the intention of the Paris Agreement's polycentric approach: trust breeds trust and ambition breeds ambition. ${ }^{39}$ The hope is that actions like net zero healthcare will help inspire the transformative action needed to avert catastrophic climate change.

Societal approaches to tackling climate change have been proposed that do not directly involve the health sector. For example, some economists favour a global carbon tax or emission caps, $4^{40}$ which theoretically could represent a more efficient use of resources. However, after decades of international negotiations, increasing global greenhouse gas emissions, and unabated global temperature rise, this approach has been found wanting, and we need to pursue all approaches in parallel.

NICE has recently committed to leading global efforts to incorporate environmental impact data into its guidance to reduce healthcare's carbon footprint. ${ }^{41}$ It is time more scholars and policy makers within healthcare priority setting seriously considered the implications of reducing carbon emission for the fair distribution of health and healthcare. Decision makers ultimately have a responsibility to consider opportunity costs when allocating resources. More fully integrating carbon emissions into established priority setting processes is a vital step on the pathway to net zero.

\section{Key messages}

- The healthcare sector is a major polluter

- It should use mechanisms of priority setting to decrease its climate impact and better protect health

- Carbon emissions should be considered alongside financial cost and efficacy in prioritising healthcare interventions

- Lifecycle analyses can improve understanding of the carbon cost of healthcare

- High income countries need to make rapid carbon reductions and facilitate universal healthcare in lower income countries

Contributors and sources: $\mathrm{AB}$ is a doctor working on climate change and health at the Bergen Centre for Ethics and Priority Setting (BCEPS). He developed the central idea of linking priority setting and decarbonising healthcare. OFN is lead editor of the fourth edition of the Disease Control Priority initiative (DCP-4). He is the guarantor.

Competing interests: We have read and understood BMJ policy on declaration of interests and have no interests to declare

Provenance and peer review: Not commissioned; externally peer reviewed.

NHS England. Greener NHS. Delivering a ‘net zero’ National Health Service. 2020.

https://www.england.nhs.uk/greenernhs/publication/delivering-a-net-zero-national-health-service/
2 Healthcare Without Harm. A road map for health care decarbonization. Health Care Climate Action, 2021. https://healthcareclimateaction.org/roadmap

COP26 Health Team. COP26 health programme: country commitments to build climate resilient and sustainable health systems. 2021. https://cdn.who.int/media/docs/default-source/climatechange/cop26-health-programme.pdf?sfvrsn=cde1b578_5

4 United Nations. Paris agreement to the United Nations Framework Convention on Climate Change. Report No. TIAS No. 16-1104. UN, 2015.

5 Kerry J. Opening statement at climate adaptation summit 2021. United States Department of State, 2021. https://www.state.gov/opening-statement-at-climate-adaptation-summit-2021/

6 Hoegh-Guldberg O, Jacob D, Taylor M, et al. Impacts of $1.5^{\circ} \mathrm{C}$ global warming on natural and human systems. In: Global warming of $1.5^{\circ} \mathrm{C}$ : an IPCC special report. 2018.

https://www.ipcc.ch/sr15/chapter/chapter-3/

7 Mercator Research Institute on Global Commons and Climate Change. Remaining carbon budget 2021. https://www.mcc-berlin.net/en/research/co2-budget.html

8 Pichler P-P, Jaccard IS, Weisz U, Weisz H. International comparison of health care carbon footprints. Environ Res Lett 2019;14:064004. doi: 10.1088/1748-9326/ab19e1

9 Sector by sector: where do global greenhouse gas emissions come from? Our World in Data 2021. https://ourworldindata.org/ghg-emissions-by-sector

10 United Nations. Health institutions join the United Nations race to zero campaign. 2021. https://unfccc.int/news/health-institutions-join-the-united-nations-race-to-zero-campaign

11 Tennison I, Roschnik S, Ashby B, etal. Health care's response to climate change: a carbon footprint assessment of the NHS in England. Lancet Planet Health 2021;5:e84-92. https://www.thelancet.com/journals/lanplh/article/PIIS2542-5196(20)30271-0/abstract. doi: 10.1016/S2542-5196(20)30271-0 pmid: 33581070

12 Thiel CL, Woods NC, Bilec MM. Strategies to reduce greenhouse gas emissions from laparoscopic surgery. Am J Public Health2018;108(Suppl 2):S158-64. doi: 10.2105/AJPH.2018.304397 pmid: 29698098

13 American College of Obstetricians and Gynecologists' Committee on Gynecologic Practice, The Society of Gynecologic Surgeons. Robot-assisted surgery for noncancerous gynecologic conditions: ACOG COMMITTEE OPINION, Number 810. Obstet Gynecol 2020;136:e22-30. doi: 10.1097/AOG.0000000000004048 pmid: 32826597

14 Thiel CL, Eckelman M, Guido R, etal. Environmental impacts of surgical procedures: life cycle assessment of hysterectomy in the United States. Environ Sci Technol 2015;49:1779-86. doi: 10.1021/es504719g pmid: 25517602

15 Sherman JD, McGain F, Lem M, Mortimer F, Jonas WB, MacNeill AJ. Net zero healthcare: a call for clinician action. BMJ 2021;374:n1323. doi: 10.1136/bmj.n1323 pmid: 34544732

16 Barraclough KA, Agar JWM. Green nephrology. Nat Rev Nephrol 2020;16:257-68. doi: 10.1038/s41581-019-0245-1 pmid: 32034297

17 Powell J. The rise of the green general practice. BMJ 2021;372:m4827. doi: 10.1136/bmj.m4827 pmid: 33531339

18 Mortimer F, Isherwood J, Wilkinson A, Vaux E. Sustainability in quality improvement: redefining value. Future Healthc J2018;5:88-93. doi: 10.7861/futurehosp.5-2-88 pmid: 31098540

19 MacNeill AJ, Lillywhite R, Brown C). The impact of surgery on global climate: a carbon footprinting study of operating theatres in three health systems. Lancet Planet Health 2017;1:e381-8. doi: 10.1016/S2542-5196(17)30162-6 pmid: 29851650

20 Quantifying hospital services by carbon footprint: a systematic literature review of patient care alternatives. Resour Conserv Recycling2020;154:104560.doi: 10.1016/j.resconrec.2019.104560.

21 McAlister S, Ou Y, Neff E, etal. The environmental footprint of morphine: a life cycle assessment from opium poppy farming to the packaged drug. BMJ Open 2016;6:e013302. doi: 10.1136/bmjopen-2016-013302 pmid: 27798031

22 Marsh K, Ganz M, Nørtoft E, Lund N, Graff-Zivin J. Incorporating environmental outcomes into a health economic model. Int J Technol Assess Health Care 2016;32:400-6. doi: 10.1017/S0266462316000581 pmid: 28065172

23 Jamison DT. Investing in health. In: Jamison DT, Breman JG, Measham AR, etal, eds. Disease control priorities in developing countries. 2nd ed. World Bank, 2006.https://www.ncbi.nlm.nih.gov/books/NBK11754/

24 Campion N, Thiel CL, DeBlois J, Woods NC, Landis AE, Bilec MM. Life cycle assessment perspectives on delivering an infant in the US. Sci Total Environ 2012;425:191-8. doi: 10.1016/j.scitotenv.2012.03.006 pmid: 22482785

25 Thiel C, Campion N, DeBlois J, Woods NC, Landis AE, Bilec MM. Life cycle assessment of medical procedures: vaginal and cesarean section births. 2012. https://ieeexplore.ieee.org/document/6228000

26 Morris DS, Wright T, Somner JEA, Connor A. The carbon footprint of cataract surgery. Eye (Lond) 2013;27:495-501. doi: 10.1038/eye.2013.9 pmid: 23429413

27 Chatterjee S, Gosselin RA. Estimating the effectiveness of a hospital's interventions in India: impact of the choice of disability weights. Bull World Health Organ 2015;93:476-82. doi: 10.2471/BLT.14.147900 pmid: 26170505

28 Baltussen R, Sylla M, Mariotti SP. Cost-effectiveness analysis of cataract surgery: a global and regional analysis. Bull World Health Organ 2004;82:338-45. pmid: 15298224

29 Close A, Robertson C, Rushton S, etal. Comparative cost-effectiveness of robot-assisted and standard laparoscopic prostatectomy as alternatives to open radical prostatectomy for treatment of men with localised prostate cancer: a health technology assessment from the perspective of the UK National Health Service. Eur Urol 2013;64:361-9.

doi: 10.1016/j.eururo.2013.02.040 pmid: 23498062 
30 Thiel CL, Schehlein E, Ravilla T, etal. Cataract surgery and environmental sustainability: Waste and lifecycle assessment of phacoemulsification at a private healthcare facility. J Cataract Refract Surg 2017;43:1391-8. doi: 10.1016/j.jcrs.2017.08.017 pmid: 29223227

31 Haripriya A, Chang DF, Reena M, Shekhar M. Complication rates of phacoemulsification and manual small-incision cataract surgery at Aravind Eye Hospital. J Cataract Refract Surg 2012;38:1360-9. doi: 10.1016/j.jcrs.2012.04.025 pmid: 22814042

32 Claxton K, Martin S, Soares M, etal. Methods for the estimation of the National Institute for Health and Care Excellence cost-effectiveness threshold. Health Technol Assess 2015;19:1-503, v-vi. doi: 10.3310/hta19140 pmid: 25692211

33 Lenzen M, Malik A, Li M, etal. The environmental footprint of health care: a global assessment. Lancet Planet Health 2020;4:e271-9. doi: 10.1016/S2542-5196(20)30121-2 pmid: 32681898

34 World Bank. CO2 emissions (metric tons per capita): low income countries, 2015. 2021 https://data.worldbank.org/indicator/EN.ATM.CO2E.PC?end=2015\&locations=XM\&start=1960

35 Fullman N, Yearwood J, Abay SM, etalGBD 2016 Healthcare Access and Quality Collaborators. Measuring performance on the Healthcare Access and Quality Index for 195 countries and territories and selected subnational locations: a systematic analysis from the Global Burden of Disease Study 2016. Lancet 2018;391:2236-71.

doi: 10.1016/S0140-6736(18)30994-2 pmid: 29893224

36 Born K, Kool T, Levinson W. Reducing overuse in healthcare: advancing Choosing Wisely. BMJ 2019;367:16317. doi: 10.1136/bmj.16317 pmid: 31690578

37 Watts N, Amann M, Arnell N, etal. The 2020 report of The Lancet Countdown on health and climate change: responding to converging crises. Lancet 2021;397:129-70. doi: 10.1016/S0140-6736(20)32290-X pmid: 33278353

38 United Nations. Population prospects. 2017. https://population.un.org/wpp/

39 Ostrom E. A polycentric approach for coping with climate change: background paper to the 2010 world development report (Policy research working paper 5095). World Bank, 2010.

40 Stern N, Stiglitz JE. Report of the high-level commission on carbon prices. World Bank, 2017. https://www.carbonpricingleadership.org/

41 National Institute for Health and Care Excellence. NICE strategy 2021 to 2026. 2021 https://static.nice.org.uk/NICE\%20strategy\%202021\%20to\%202026\%20-\%20Dynamic,\%20Collaborative,\%20Excellent.pdf 